\title{
Cadmium(II) Capture Using Amino Functionalized Hydrogel with Double Network Interpenetrating Structure: Adsorption Behavior Study
}

\section{Sihua Liu}

Hunan University of Technology

Haifei Wang

Hunan University of Technology

Jue $\mathrm{Hu}$

Hunan University of Technology

Yue Li

Hunan University of Technology

guiyin zhou ( $\nabla$ gyzhou@hut.edu.cn )

Hunan University of Technology https://orcid.org/0000-0002-6913-0909

\section{Research Article}

Keywords: hydrogel, cadmium ion, adsorption behavior

Posted Date: May 19th, 2021

DOl: https://doi.org/10.21203/rs.3.rs-531371/v1

License: (9) This work is licensed under a Creative Commons Attribution 4.0 International License.

Read Full License 


\title{
Cadmium(II) Capture Using Amino Functionalized Hydrogel with
}

\section{Double Network Interpenetrating Structure: Adsorption Behavior Study}

\author{
Sihua liu ${ }^{\mathrm{a}, 1}$, Haifei Wang ${ }^{\mathrm{a}, 1}$, Jue Hu${ }^{\mathrm{a}}$, Yue $\mathrm{Li}^{\mathrm{b}}$, Guiyin $\mathrm{Zhou}^{\mathrm{a},{ }^{*}}$ \\ ${ }^{\text {a }}$ College of Life Science and Chemistry, Hunan University of Technology, Zhuzhou, 412007, PR \\ China \\ ${ }^{\mathrm{b}}$ School of Materials and Chemical Engineering, Henan University of Engineering, Zhengzhou, \\ 450007, PR China \\ ${ }^{1}$ The authors contributed equally to this work \\ ${ }^{*}$ Correspongding author \\ E-mail: gyzhou@hut.edu.cn
}

\begin{abstract}
Heavy metal pollution caused by the indiscriminate disposal of toxic heavy metal wastewater has become one of the serious water environmental issues. In this study, a novel $\mathrm{NH}_{2}$-PAA/Alginate hydrogel with double network interpenetrating structure was constructed with alginate, acrylic acid, and other raw materials. Characterized by SEM, this hydrogel shows a three-dimensional porous structure, which would be useful in adsorption process for its high diffusion coefficient. The results of adsorption experimental show that the $\mathrm{NH}_{2}-\mathrm{PAA} /$ Alginate possessed the well adsorption capacity when $\mathrm{pH}$ above 3.5 , the maximum adsorption capacity calculated by Langmuir was $176.5 \mathrm{mg} / \mathrm{g}$, the adsorption equilibrium can be achieved within 150 min. In addition, the $\mathrm{NH}_{2}-\mathrm{PAA} /$ Alginate has good recycling ability and stability. The results of XPS analysis reveal that the $\mathrm{Cd}(\mathrm{II})$ exchanged with $\mathrm{Ca}$ (II) and then coordinated with amino and hydroxyl groups in $\mathrm{NH}_{2}-\mathrm{PAA} /$ Alginate. The $\mathrm{NH}_{2}-$ PAA/Alginate hydrogel can deal with all kinds of heavy metal ions and is a potential material for heavy metal adsorption.
\end{abstract}


Key words: hydrogel; cadmium ion; adsorption behavior. 


\section{Introduction}

Water plays a vital role in the development of human society. While the increasing worldwide contamination of water systems has become one of the key environmental facing humanity [1]. According to "The Analysis Report of China's Industrial Effluent Treatment in 2019", the industrial wastewater discharge accounts for $23.55 \%$ of the total wastewater discharge in China in 2017 , which is 18.16 billion tons. The nondegradable and toxic heavy metal ions from the industrial effluent, such as cadmium ion, can accumulate in the body along with the biological chain, causing a serious of damage to human health. For example, damage central nervous system, liver and kidneys [2]. Therefore, the removal of such toxic metal ions from industrial effluent is becoming a crucial issue. Various treatment technologies, such as chemical precipitation [3], solvent extraction, reverse osmosis [4], ion-exchange [5], filtration [6], electrodialysis [7], have been employed to remove heavy metal ions from industrial effluent. While adsorption technology is regarded as one of the most promising technologies owning to its low cost and easy operate.

Still, there are many problems in practical application of adsorbent. For example, the granular adsorption such as activated carbon and chelating resin, have a large number of micropores and mesopores due to their high specific surface area [8], the slow internal diffusion rates of these adsorbents dominated by Knudsen diffusion seriously limit their overall kinetics and the equilibrium times commonly require some hours [9]. In addition, the granular materials are easily subject to blocking and burial of adsorption sites, resulting in partial loss of adsorption performance [10]. Although the nano-adsorbent possess the high surface energy which can accelerate the adsorption process [11], the difficult to separate for the nanoscale could result in the increase of operation cost and secondary pollution of the environment [12]. Magnetic nanoadsorbents solve the problem of nano material recovery [13], while the magnetic particles such as iron, cobalt, nickel particles are easy to fall off from the nanoadsorbent in the adsorption process [14]. Additionally, the inefficient regeneration of magnetic nano-adsorbents under acidic conditions greatly limits their practical 
applications [15]. Therefore, it is of great significance to find a kind of adsorption material with high adsorption performance, easy separation and regeneration.

Polymer hydrogel is a material with characteristics of solid and liquid [16]. The diffusion coefficient of molecules in three-dimensional networks of hydrogel is close to that of water [17], although they possess macroscopical geometric structure. Sun group reported an extremely stretchable and tough dual network (DN) hydrogels by combining weak and strong crosslinks in 2012 [18]. The combination of relatively high stiffness, high toughness and recoverability of stiffness and toughness, along with an easy method of synthesis, make these materials ideal candidates for further investigation. Therefore, double network hydrogel has attracted much attention in many fields such as drug delivery [19], tissue engineering [20], environmental remediation $[21]$

In this study, a novel amino-group functionalized $\mathrm{NH}_{2}-\mathrm{PAA} /$ Alginate $\mathrm{DN}$ hydrogel adsorption was designed and prepared using simple free-radical polymerization and modification. The physico-chemical properties of $\mathrm{NH}_{2}-\mathrm{PAA} /$ Alginate hydrogel were characterized using SEM, FTIR and XPS analyses. The influence of initial $\mathrm{pH}$ of the solution, ionic strength, adsorbate concentration, adsorption time and temperature on $\mathrm{NH}_{2}$-PAA/Alginate hydrogel were studied, and the adsorption performance of $\mathrm{NH}_{2}-$ PAA/Alginate hydrogel for $\mathrm{Cd}(\mathrm{II})$ was also evaluated. Furthermore, the adsorption mechanism was also discussed in detail.

\section{Experimental part}

\subsection{Materials}

Sodium alginate (viscosity $200 \pm 20 \mathrm{mPa} . \mathrm{s}$ ) was purchased from Tianjin Guangfu Fine Chemical Research Institute; Acrylic acid (analysis pure) was purchased from Shandong Qilu pharmaceuticals company and distilled under reduced pressure before use. Ammonium persulfate and triethylenetetramine were analytically pure and purchased from Sinopharm Chemical Reagent Co., Ltd; N,N-Methylenebisacrylamide, sodium bisulfite, calcium chloride, epichlorohydrin, analytically pure, purchased from 
Shandong West Asia Chemical Industry Co., Ltd and used as received. All aqueous solutions were prepared with deionized water.

\subsection{Preparation of hydrogel}

$\mathrm{NH}_{2}$-PAA/Alginate hydrogel was prepared using radical copolymerization and surface functional modification. As depicted in Fig. 1, $1.2 \mathrm{~g}$ acrylic acid and $0.3 \mathrm{~g}$ sodium alginate were added to $6 \mathrm{ml}$ deionized water under stirring. Then the mixed solution, $0.025 \mathrm{~g}$ ammonium persulfate (initiator), $0.020 \mathrm{~g}$ sodium bisulfite (redox initiation system) and $0.025 \mathrm{~g} \mathrm{~N}, \mathrm{~N}-$ Methylenebisacrylamide (cross-linking agent) were added into a glass reactor. After ultrasonic under nitrogen atmosphere, the sealed reactor was placed in a water bath at $40^{\circ} \mathrm{C}$ for $2 \mathrm{~h}$ to complete gelation process. The synthesized hydrogel was freeze-dried for $24 \mathrm{~h}$ and immersed in $5 \mathrm{wt} \% \mathrm{CaCl}_{2}$ solution for $2 \mathrm{~h}$ to cross-link the alginate network and got the PAA/Alginate hydrogel.

Next, after an immersion into $6 \mathrm{~mL}$ of dimethyl sulfoxide solution containing 0.1 $\mathrm{g} \mathrm{NaOH}$ and $0.4 \mathrm{~mL}$ epichlorohydrin for $1 \mathrm{~h}$ at $60^{\circ} \mathrm{C}$, the PAA/Alginate was further immersed into $6 \mathrm{~mL}$ of deionized water containing sodium hydroxide (20 wt $\%)$ and triethylenetetramine $(0.6 \mathrm{~mL})$ for $6 \mathrm{~h}$ at $60^{\circ} \mathrm{C}$ to obtain $\mathrm{NH}_{2}-\mathrm{PAA} /$ Alginate, which was washed with deionized water to remove unreacted reagents.

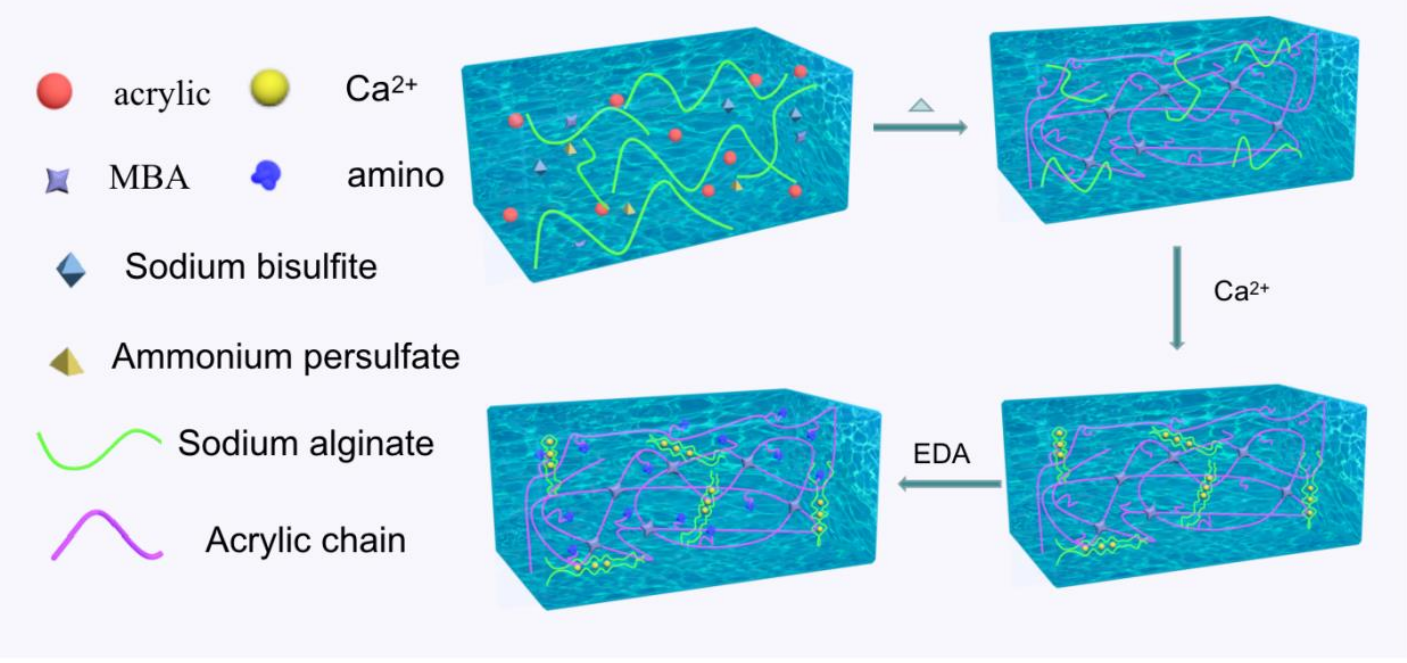

Fig. 1 Mechanisms of converting the composite into $\mathrm{NH}_{2}-\mathrm{PAA} /$ Alginate DN hydrogels.

\subsection{Characterization}


The chemical structure of the samples was analyzed by Fourier transform infrared spectroscopy (FTIR, Nicolet 5700, Thermo Electron Scientific Instruments Corp. American). After the sample was ground into power with $\mathrm{KBr}$ and pressed into pellet, the test was analyzed in the range of $4000 \sim 500 \mathrm{~cm}^{-1}$. The morphological features of freeze-dried $\mathrm{NH}_{2}$-PAA/Alginate examined by scanning electron microscope (SEM, MIRA3, Tescan Ltd., Czech Republic). The thermal stability of $\mathrm{NH}_{2}-\mathrm{PAA} /$ Alginate xerogel was analyzed by thermogravimetric analysis (TGA, TG/DTA7300, Hitachi, Ltd., Japan) from room temperature to $600^{\circ} \mathrm{C}$ under a nitrogen atmosphere at a heating rate of $10^{\circ} \mathrm{C} / \mathrm{min}$. The surface chemistry of $\mathrm{NH}_{2}$-PAA/Alginate before and after adsorbing Cd(II) was determined by X-ray photoelectron spectroscope (ESCALAB 250XI, Thermo Electron Scientific Instruments Corp. American). The compression experiment was implemented by electronic universal material testing machine (AGXplus, Shimadzu Ltd., Japan) with compression rate of $2 \mathrm{~mm} / \mathrm{min}$. The zero charge point of the hydrogels was measured by $\Delta \mathrm{pH}$ drift method. The $1 \mathrm{wt} \%$ xerogels were added into a series of solution with different $\mathrm{pH}$ and $0.01 \mathrm{M} \mathrm{NaCl}$. After $12 \mathrm{~h}$ at $25^{\circ} \mathrm{C}$, the $\mathrm{pH}$ of the solution was measured again, and the intersection of curve with $\mathrm{X}$ axis of $\Delta \mathrm{pH} v s . \mathrm{pH}$ was the zero charge point of $\mathrm{NH}_{2}-\mathrm{PAA} /$ Alginate. The swelling experiment was performed by immersing the hydrogels in an excess of water to reach swelling equilibrium at $25^{\circ} \mathrm{C}$.

\subsection{Batch adsorption experiments}

The batch adsorption experiments were conducted using $1 \mathrm{~g} / \mathrm{L} \mathrm{NH}_{2}-\mathrm{PAA} /$ Alginate dry gel. Analytical grade $\mathrm{Cd}\left(\mathrm{NO}_{3}\right)_{2}$ were employed to prepare the $\mathrm{Cd}(\mathrm{II})$ stock solutions. The $\mathrm{pH}$ values of solution were adjusted by dilute $\mathrm{HCl}$ or $\mathrm{NaOH}$ solutions. $\mathrm{NaCl}, \mathrm{MgCl}_{2}$ or $\mathrm{CaCl}_{2}$ were added as background electrolyte. After the suspensions were shaken under $160 \mathrm{rpm}$ for $4 \mathrm{~h}$, the concentrations of residuary $\mathrm{Cd}(\mathrm{II})$ in supernatant were measured by an atomic absorption spectrometer (AAS, AA-7020, Beijing Dongxi Analytical Instrument Co., Ltd., China). For the selectivity experiment, the mixed solution contains $\mathrm{Cu}(\mathrm{II}), \mathrm{Cd}(\mathrm{II}), \mathrm{Pb}(\mathrm{II}), \mathrm{Zn}(\mathrm{II}), \mathrm{Mn}(\mathrm{II})$ and $\mathrm{Ni}(\mathrm{II})$ ions, and the each ion concentration was $50 \mathrm{mg} / \mathrm{L}$, the $\mathrm{pH}$ of the solution kept 5.0 \pm 0.1 . For the regeneration 
study, the $\mathrm{Cd}-\mathrm{NH}_{2}-\mathrm{PAA} /$ Alginate was eluted with $0.1 \mathrm{M} \mathrm{HCl}$ solution, then regenerated with $0.1 \mathrm{M} \mathrm{NaOH}$ solution, and washed with deionized water to neutral. The detailed experimental conditions were listed in the captions of figures for different experiments.

\subsection{Data analysis}

All the adsorption experiments were repeated twice. The equilibrium adsorption capacity $q_{\mathrm{e}}\left(\mathrm{mg} \cdot \mathrm{g}^{-1}\right)$, adsorption efficiency $E(\%)$, distribution adsorption coefficient $K_{\mathrm{d}}$ $\left(\mathrm{L} \cdot \mathrm{g}^{-1}\right)$, and the swelling rate $(S R)$ were calculated according to the following formula:

$$
\begin{aligned}
& q_{\mathrm{e}}=V\left(C_{0}-C_{\mathrm{e}}\right) / m \\
& E=\left(C_{0}-C_{\mathrm{e}}\right) / C_{0} \times 100 \% \\
& K_{\mathrm{d}}=q_{\mathrm{e}} / C_{\mathrm{e}} \\
& S R=\left(W_{\mathrm{t}}-W_{\mathrm{d}}\right) / W_{\mathrm{t}} \times 100 \%
\end{aligned}
$$

where $V$ is the volume of the solution, $m$ is the weight of the dry $\mathrm{NH}_{2}-\mathrm{PAA} /$ Alginate, $C_{0}$ and $C_{\mathrm{e}}$ are the initial and equilibrium concentrations of $\mathrm{Cd}(\mathrm{II})$ ions. The $W_{\mathrm{t}}$ represents the mass of gel in swollen state at time $t$, and $W_{\mathrm{d}}$ is the mass of $\mathrm{NH}_{2}-$ PAA/Alginate xerogel.

\subsection{Model Fitting}

Kinetic models including pseudo-first-order, pseudo-second-order model and intraparticle diffusion model were employed to fit the experimental data, and the mathematical equations were expressed as follow:

$$
\begin{gathered}
q_{\mathrm{t}}=q_{\mathrm{e}}\left(1-\exp \left(-k_{1} t\right)\right) \\
q_{\mathrm{t}}=q_{\mathrm{e}}\left(1-\frac{1}{1+q_{\mathrm{e}} k_{2} t}\right) \\
q_{t}=k_{p} t^{0.5}
\end{gathered}
$$

where $q_{\mathrm{t}}\left(\mathrm{mg} \cdot \mathrm{g}^{-1}\right)$ is adsorption capacity at $t(\mathrm{~min}), k_{1}\left(\mathrm{~L} \cdot \mathrm{min}^{-1}\right), k_{2}\left(\mathrm{~g} \cdot(\mathrm{mg} \cdot \mathrm{min})^{-1}\right)$ and 
$k_{\mathrm{p}}\left(\mathrm{min}^{-1}\right)$ are the corresponding adsorption rate constants.

Isothermal adsorption model including Langmuir, Freundlich, and Temkin model were used to fit the adsorption isotherms. The correlation coefficients $\left(\mathrm{R}^{2}\right)$ were used for comparing the model applicability. The parameters of isothermal adsorption were calculated by the following equations:

$$
\begin{gathered}
q_{e}=\frac{q_{\max } \cdot K_{L} \cdot C_{e}}{1+K_{L} \cdot C_{e}} \\
q_{e}=K_{F} C_{e}^{1 / n_{\mathrm{F}}} \\
q_{e}=\left(R T / b_{T}\right) \ln A_{T}+\left(R T / b_{T}\right) \ln C_{e} \\
q_{e}=\frac{K_{L F} C_{e}^{1 / n}}{1+a_{L F} C_{e}^{1 / n}}
\end{gathered}
$$

where $q_{\max }\left(\mathrm{mg} \cdot \mathrm{g}^{-1}\right)$ is the maximum adsorption, $K_{\mathrm{L}}\left(\mathrm{L} \cdot \mathrm{mg}^{-1}\right), K_{\mathrm{F}}\left(\mathrm{L} \cdot \mathrm{mg}^{-1}\right)$ and $K_{\mathrm{LF}}$ $\left(\mathrm{L} \cdot \mathrm{mg}^{-1}\right)$ are the isotherm adsorption constant, respectively, $n_{\mathrm{F}}$ is the adsorption intensity, the $A$ T $\left(\mathrm{L} \cdot \mathrm{g}^{-1}\right)$ is the Temkin isotherm equilibrium binding constant and $b_{\mathrm{T}}$ $\left(\mathrm{J} \cdot \mathrm{mol}^{-1}\right)$ is the constant related to heat of sorption.

\section{Results and discussion}

\subsection{Characterization of hydrogel}

The freeze-dried $\mathrm{NH}_{2}-\mathrm{PAA} /$ Alginate aerogel was used to characterize the internal structure of SEM, and the result is shown in Fig. 2a. As shown by SEM image, the $\mathrm{NH}_{2}-$ PAA/Alginate exhibited a three-dimensional porous structure, and such a morphological feature would improve the exposure of the adsorption sites and the diffusion of metal ions [22]. The bulk $\mathrm{NH}_{2}$-PAA/Alginate (inset image in Fig. 2a) could be cut into different shape in need as well as easy separation. The compressive test of $\mathrm{NH}_{2}$-PAA/Alginate was investigated with gradually increasing strain (ع) (Fig. 2b). It can be seen that the $\mathrm{NH}_{2}$-PAA/Alginate achieved a compression stress of $724 \mathrm{Kpa}$ when 
the load deformation was $36 \%$. After the immediate second cycle, the compression stress was up to $1.3 \mathrm{Mpa}$ at $\varepsilon=51 \%$, meanwhile, the compression stress of second test is not as high as that of first, illustrating that the hysteresis was caused by unzipping the network of ionic cross-links [23]. Significantly, the guluronic acid in alginate chains can form ionic crosslinks through $\mathrm{Ca}$ (II), and the electrostatic interaction may enable synergistic energy dissipation [24].
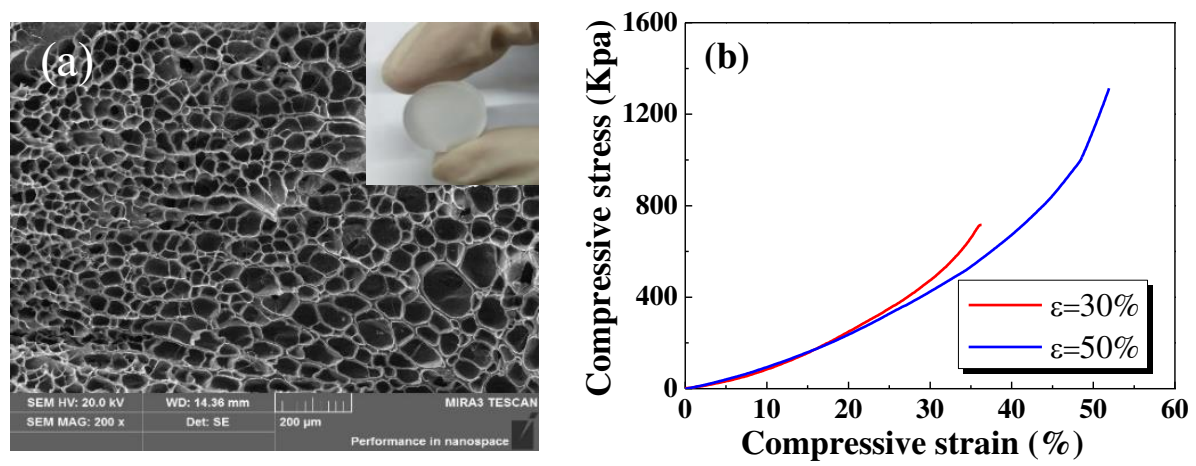

Fig. 2 (a) The SEM image of $\mathrm{NH}_{2}$-PAA/Alginate. (b) Typical consecutive loading curves with gradually increased strain on $\mathrm{NH}_{2}-\mathrm{PAA} /$ Alginate.

The group structure of the sample was analyzed by FTIR. As shown in Fig. 3a, the following functional groups were identified in PAA/Alginate: O-H, N-H stretching vibrations $\left(3420 \mathrm{~cm}^{-1}\right), \mathrm{C}-\mathrm{H}$ stretching vibrations $\left(2930 \mathrm{~cm}^{-1}\right), \mathrm{C}=\mathrm{O}$ stretching vibration $\left(1670 \mathrm{~cm}^{-1}\right)$, C-O stretching vibrations $\left(1300 \sim 1100 \mathrm{~cm}^{-1}\right)$ [25]. Compared with that of PAA/Alginate, two broader adsorptions appeared in $\mathrm{NH}_{2}-\mathrm{PAA} /$ Alginate at 3180 and $1410 \mathrm{~cm}^{-1}$, which corresponded to the stretching and bending vibration of amino N-H, respectively [26]. The FTIR spectra proved the existence of carboxyl and amino groups in $\mathrm{NH}_{2}-\mathrm{PAA} /$ Alginate. The XPS results of $\mathrm{NH}_{2}-\mathrm{PAA} /$ Alginate also confirmed the existence of oxygen- and amino-containing functional groups, a quantitative amount of the elements was determined by XPS element analysis and the results of the atomic content are listed in Table 1. 

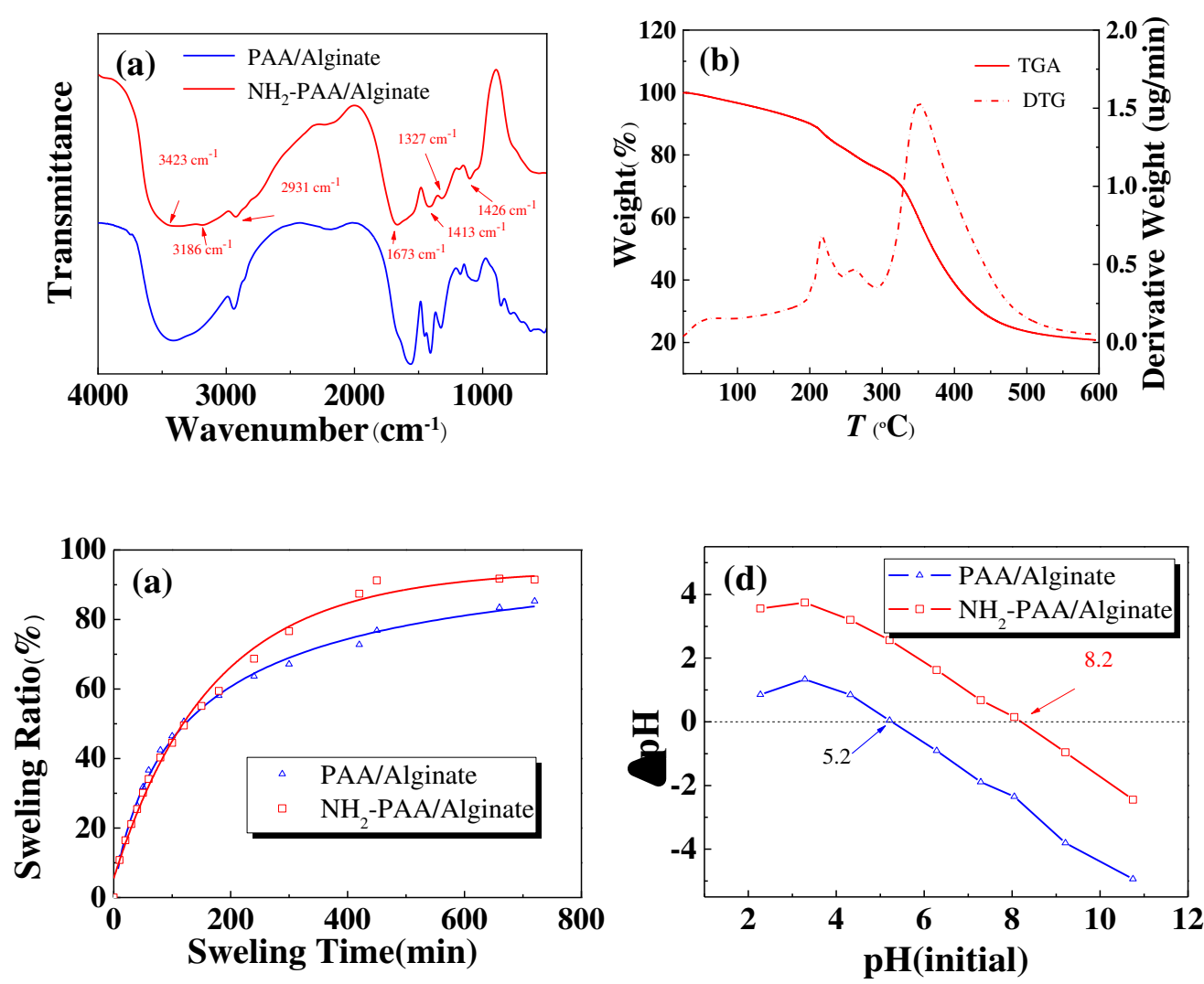

Fig. 3 (a) The FTIR spectra. (b) The TGA and DTG curves. (c) The swelling curves. (d) The $\mathrm{pH}_{\mathrm{pzc}}$ measure of the hydrogel by $\Delta \mathrm{pH}$ method.

Table 1 XPS analysis of element in the $\mathrm{NH}_{2}-\mathrm{PAA}$ /Alginate

\begin{tabular}{ccccc}
\hline \multirow{2}{*}{ Name } & \multicolumn{2}{c}{$\mathrm{NH}_{2}$-PAA/Alginate } & \multicolumn{2}{c}{$\mathrm{Cd}(\mathrm{II})-\mathrm{NH}_{2}$-PAA/Alginate } \\
\cline { 2 - 5 } & Atomic \% & PP At. \% & Atomic \% & PP At. \% \\
\hline $\mathrm{Cls}$ & 63.95 & 61.23 & 59.58 & 54.03 \\
$\mathrm{O} 1 \mathrm{~s}$ & 20.43 & 20.66 & 26.53 & 29.05 \\
$\mathrm{~N} 1 \mathrm{~s}$ & 15.62 & 18.11 & 12.03 & 16.3 \\
$\mathrm{Ca}$ & 1.6 & 0.5 & 0.7 & 0.11 \\
$\mathrm{Cd}$ & - & - & 1.16 & 0.51
\end{tabular}

Fig. 3b shows the integral results from the thermogravimetric analysis (TGA) and the differential thermogravimetric data (DTG) analysis of $\mathrm{NH}_{2}-\mathrm{PAA} /$ Alginate. The peak in DTG curve represents the temperature where the degradation rate is maximum for degradation stage in the whole process [27]. It can be seen that there are two 
pyrolysis stages of the $\mathrm{NH}_{2}-\mathrm{PAA} /$ Alginate, the first thermal degradation process occurred in the temperature range $200 \sim 300^{\circ} \mathrm{C}$, which is attributed to the degradation of the amino, carboxyl and hydroxyl groups, as volatile gases were released [28]. The second stage occurred in the range $300 \sim 450^{\circ} \mathrm{C}$, and is attributed to the depolymerization of polymer and formation of a carbonaceous residue.

The swelling behavior of hydrogels is shown in Fig. 3c. It can be seen that the SR of PAA/Alginate was about $85 \%$ at equilibrium state. After amino modification, the hydrophilic ability of $\mathrm{NH}_{2}-\mathrm{PAA} /$ Alginate increases, and the swelling rate raised to $90 \%$, while the hydrogel still maintains good mechanical property. Moreover, the metal ions have faster diffusion rate in the hydrogel with the higher water content [29]. The result of the zero charge point experiment is shown in Fig. $3 \mathrm{~d}$. The zero charge point of $\mathrm{NH}_{2}-$ PAA/Alginate is 8.2, higher than that of PAA/Alginate (zero charge point is 5.2), which is due to the introduction of amine groups.

\subsection{Effect of environmental conditions}

In order to investigate the influence of environmental conditions on the adsorption process, the adsorption experiments of $\mathrm{Cd}(\mathrm{II})$ on $\mathrm{NH}_{2}-\mathrm{PAA} /$ Alginate under different $\mathrm{pH}$, different ion species $(\mathrm{Na}, \mathrm{Mg}, \mathrm{Ca})$ and ionic strength were studied. The $\mathrm{pH}$ of bulk solution precipitation ( $\mathrm{pH}_{\mathrm{BSP}}$ ) for $\mathrm{Cd}(\mathrm{II})$ with initial concentration of $50 \mathrm{mg} / \mathrm{L}$ was 8.51 , and no precipitation occurred at $\mathrm{pH}$ below $\mathrm{pH}_{\mathrm{BSP}}$. As shown in Fig. 4, the adsorption capacity of $\mathrm{Cd}(\mathrm{II})$ onto $\mathrm{NH}_{2}-\mathrm{PAA} /$ Alginate at $\mathrm{pH} 1.5$ could be negligible. The adsorption capacity sharply increased with increasing $\mathrm{pH}$ at range of 2 3.5, and finally retained about $48 \%$ at $\mathrm{pH}$ above 4 . Generally, the solution $\mathrm{pH}$ is lower than the zero charge point (the value of $\mathrm{NH}_{2}$-PAA/Alginate is 8.2 ), the surface of adsorption is positively charged for the protonation reaction, which is unfavorable for adsorption process due to the electrostatic repulsion towards positively charged metal ions [30]. while, the adsorption capacity of $\mathrm{NH}_{2}$-PAA/Alginate could reach to adsorption saturation at $\mathrm{pH}$ above 4 , indicating that the adsorption process of $\mathrm{Cd}$ (II) on $\mathrm{NH}_{2}$ PAA/Alginate was dominated by chemical adsorption rather than electrostatic interactions [31]. In the range of $\mathrm{pH} 2.0 \sim 3.5$, the protonation reaction will compete 
with the heavy metal ion adsorption, and the adsorption process can be described as a liquid-solid interface ion exchange process [32]:

$$
n \overline{\operatorname{SurH}}+C d(I I) \Leftrightarrow \overline{\operatorname{Sur}_{n} C d(I I)}+n H^{+}
$$

According to the thermodynamic equilibrium constant and distribution coefficient, the following relation can be deduced:

$$
\log K_{d}=\log K_{e q}+n \log [\overline{\text { SurH }}]+n p H
$$

where Sur is the surface of $\mathrm{NH}_{2}-\mathrm{PAA} /$ Alginate, the overline labels refer to species on $\mathrm{NH}_{2}$-PAA/Alginate, $K_{\text {eq }}$ is the thermodynamic equilibrium constant. The $\log K_{\mathrm{d}} v s . \mathrm{pH}$ was plotted in Fig. 4c. The slope of the linear plot is close to 1, suggesting that the adsorption process involved with the exchange of one protons to aqueous phase when forming one $\mathrm{Cd}(\mathrm{II})$ complex. In fact, the $\mathrm{Cd}(\mathrm{II})$ also exchanges $\mathrm{Ca}$ (II) in $\mathrm{NH}_{2}-$ PAA/Alginate in the adsorption process, which could be illustrated from the analysis of the elements in XPS before and after gel adsorption (Table 1).
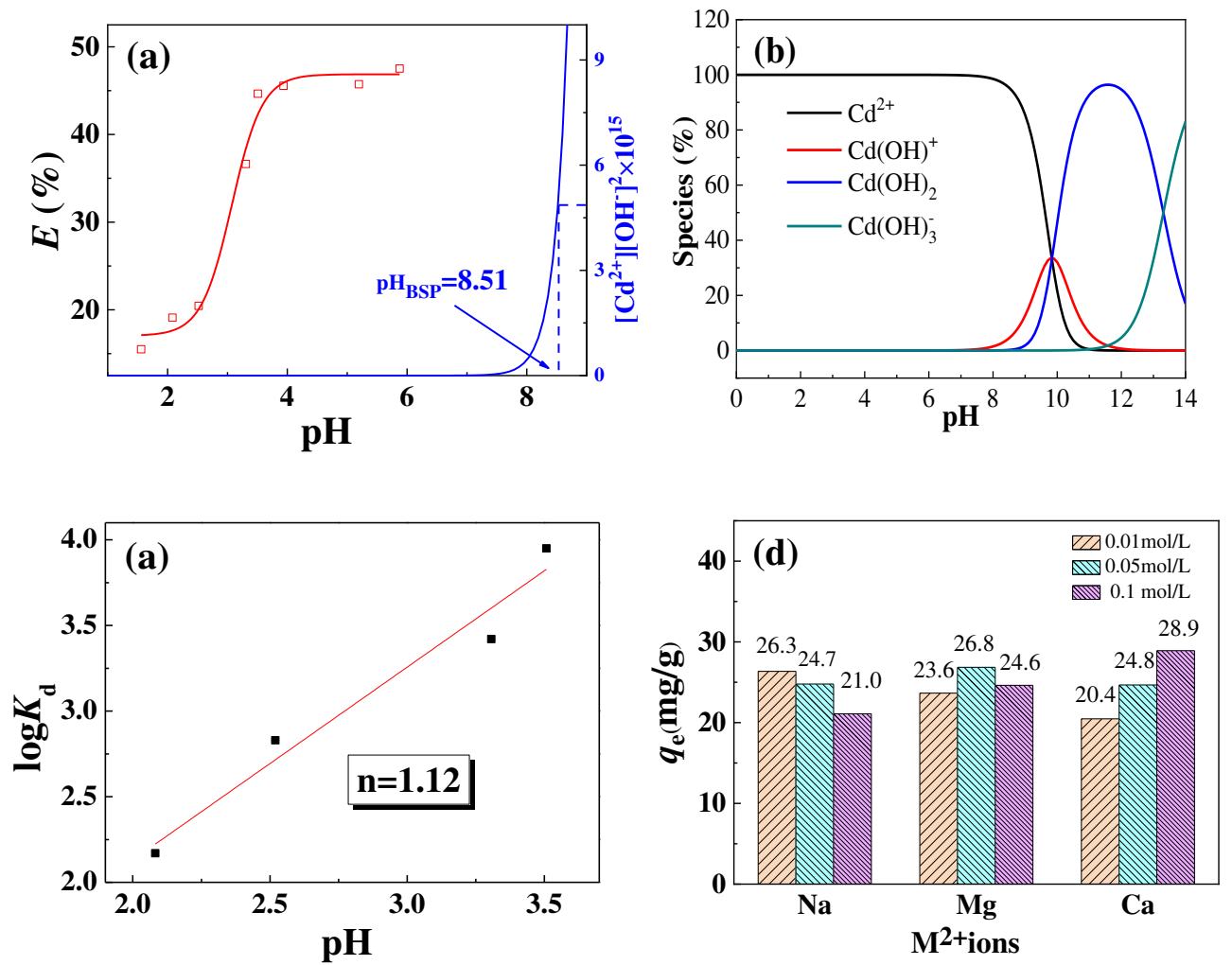

Fig. 4 (a) Effect of $\mathrm{pH}$ on $\mathrm{Cd}(\mathrm{II})$ adsorption by $\mathrm{NH}_{2}$-PAA/Alginate $\left(C_{0}=50 \mathrm{mg} / \mathrm{L}, t=4 \mathrm{~h}, T=298\right.$ 
K). (b) Distribution of radionuclide species in aqueous solutions. (c) Linear plot of $\log K_{\mathrm{d}}$ and $\mathrm{pH}$.

(d) Effect of ion species and ionic strength on adsorption for Cd(II) $\left(C_{0}=50 \mathrm{mg} / \mathrm{L}, t=4 \mathrm{~h}, T=298\right.$

$$
\mathrm{K}, \mathrm{pH}=6.0) \text {. }
$$

Alkali metal and alkaline-earth metal ions are usually abundantly present in the actual industrial effluent. Although these ions are nontoxic and harmless, the competition adsorption between these ions and $\mathrm{Cd}(\mathrm{II})$ was observed. Fig. $4 \mathrm{~d}$ shows the effects of $\mathrm{Na}(\mathrm{I}), \mathrm{Mg}(\mathrm{II})$ and $\mathrm{Ca}(\mathrm{II})$ on $\mathrm{Cd}(\mathrm{II})$ uptake by $\mathrm{NH}_{2}-\mathrm{PAA} / \mathrm{Alginate}$. It can be seen that all ions in solution had small effect on $\mathrm{Cd}(\mathrm{II})$ adsorption. The increasing the concentration of $\mathrm{Na}(\mathrm{I})$, the adsorption efficiency of $\mathrm{Cd}(\mathrm{II})$ decreased, which could mainly cause by the electrostatic repulsion [33]. While the uptake of Cd(II) increase when increasing of $\mathrm{Mg}(\mathrm{II})$ and $\mathrm{Ca}(\mathrm{II})$ concentration, this phenomena could be illustrated the formation of ionic atmosphere at higher ion concentration and reduced impact on $\mathrm{Cd}(\mathrm{II})$ adsorption.

\subsection{Adsorption kinetics}

Adsorption kinetics is important in the prediction of the adsorption rate, which is highly demanded for adsorbents in practical application. The effect of time on the $\mathrm{Cd}(\mathrm{II})$ adsorption by the $\mathrm{NH}_{2}-\mathrm{PAA} /$ Alginate is presented in Fig. 5. The adsorption of $\mathrm{Cd}(\mathrm{II})$ on the $\mathrm{NH}_{2}-\mathrm{PAA} /$ Alginate increased rapidly within $100 \mathrm{~min}$ and reached adsorption equilibrium in approximately $150 \mathrm{~min}$. For bulk material-based adsorbent, the adsorption rate is faster than that of most common granular adsorbents. Obviously, the fast adsorption rate of $\mathrm{NH}_{2}$-PAA/Alginate should owe to the three-dimensional network, porous structure and its excellent water penetration which is highly accessible to $\mathrm{Cd}(\mathrm{II})$ [34].

In order to analyze the adsorption rate of $\mathrm{Cd}(\mathrm{II})$ on $\mathrm{NH}_{2}$-PAA/Alginate, the pseudo-first-order, pseudo-second-order model and intraparticle diffusion model were employed to fit the experimental data. The fitted kinetic curves are shown in Fig. 5, and the fitted kinetic parameters are summarized in Table 2. The fitting results show that the correlation coefficients were 0.9383 for pseudo-first-order and 0.9539 for pseudo- 
second-order, respectively. Obviously, the pseudo-second-order model gave the more significant goodness-of-fit, implying that the rate-limiting step could involve the chemical adsorption.

Generally, the adsorption process follows three steps of external diffusion, intraparticle diffusion and adsorption before reaching equilibrium. To understand the dominating step of adsorption, the intraparticle diffusion model could be employed to describe adsorption process. Two set of line segments were observed in the intraparticle diffusion model curves. According to this model, if intraparticle diffusion is the ratecontrolling step, the first line with larger slope should pass through the origin [35]. While the above results are not in accord with the experiments, revealing that intraparticle diffusion was not the rate-limiting step whereas all the steps functioned simultaneously.
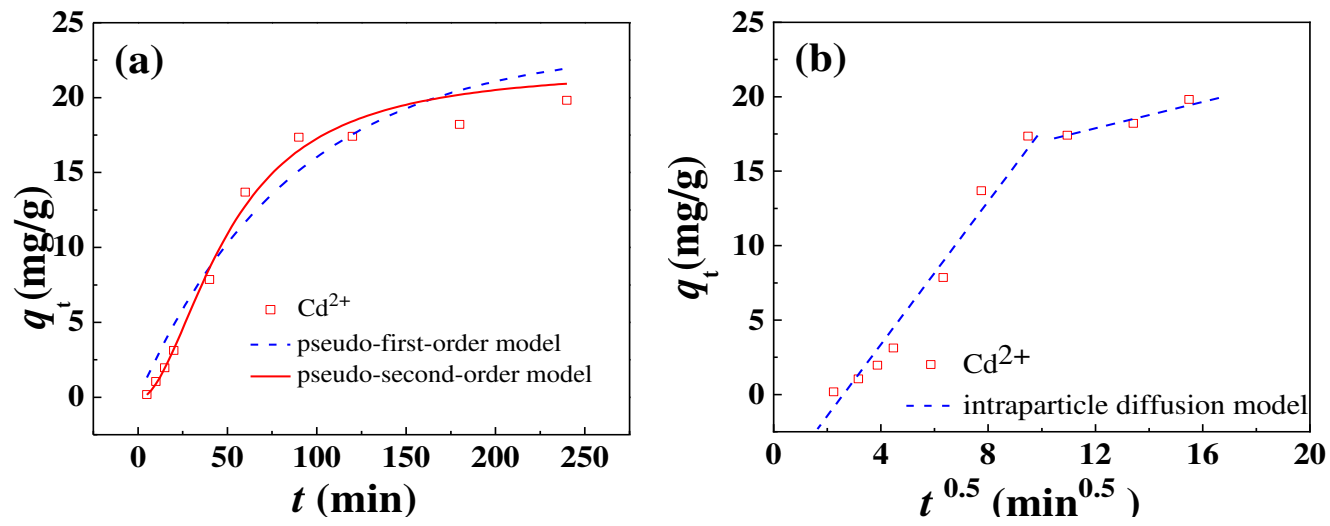

Fig. 5 Time-dependent Cd(II) sorption on hydrogel, the data are fittings to the Pseudo-first-order, Pseudo-second-order models and intraparticle diffusion model $\left(C_{0}=50 \mathrm{mg} / \mathrm{L}, T=25^{\circ} \mathrm{C}, \mathrm{pH}=6.0\right)$.

Table 2 Constants for the kinetic sorption data using different sorption models.

\begin{tabular}{cccc}
\hline & \multicolumn{3}{c}{ Adsorbent kinetic parameter } \\
\cline { 2 - 4 } Dynamic adsorption model & $K$ & $q_{\mathrm{e}}$ & $\mathrm{R}^{2}$ \\
\cline { 2 - 4 } & & 21.05 & 0.9383 \\
First order kinetic model & 0.013 & 29.19 & 0.9539 \\
\hline
\end{tabular}

\subsection{Adsorption isotherms}


The adsorption capacity of an adsorbent is usually evaluated by isothermal adsorption experiment, The isothermal adsorption data of $\mathrm{NH}_{2}-\mathrm{PAA} /$ Alginate with different concentrations of $\mathrm{Cd}(\mathrm{II})$ at $25^{\circ} \mathrm{C}$ are shown in Fig. 6. Obviously, the adsorption capacity increased with increasing $\mathrm{Cd}(\mathrm{II})$ concentrations, and finally approached the adsorption equilibrium at about $130 \mathrm{mg} / \mathrm{g}$. To further study on the adsorption behavior, the Langmuir, Freundlich, Temkin and Langmuir-Freundlich isotherms were used to describe the adsorption of $\mathrm{Cd}(\mathrm{II})$ on $\mathrm{NH}_{2}-\mathrm{PAA} /$ Alginate. The fitting curve of four models are shown in Fig. $6 \mathrm{a}$ and $\mathrm{b}$ and the corresponding parameters are listed in Table 3. The fitting results show that the correlation coefficient $\left(\mathrm{R}^{2}=0.9808\right)$ for LangmuirFreundlich model was higher than that for the other three models, indicating the Langmuir-Freundlich equation was suitable to describe the adsorption of $\mathrm{Cd}(\mathrm{II})$, and the adsorption process involved the physical adsorption and monolayer adsorption of $\mathrm{Cd}(\mathrm{II})$ on $\mathrm{NH}_{2}-\mathrm{PAA} /$ Alginate [36], such as ion exchange adsorption and coordination adsorption.
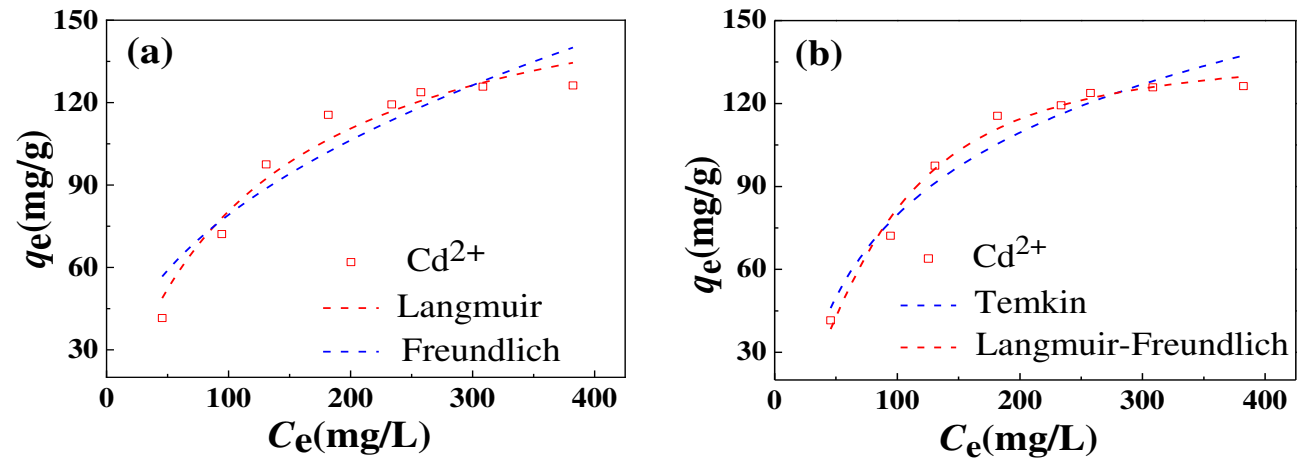

Fig. 6 The isothermal adsorption curves of $\mathrm{Cd}(\mathrm{II})$ by $\mathrm{NH}_{2}$-PAA/Alginate $(t=4 \mathrm{~h}, T=298 \mathrm{~K}, \mathrm{pH}=$ $6.0)$.

Table 3 Isotherm parameters of $\mathrm{Cd}(\mathrm{II})$ adsorption on the $\mathrm{NH}_{2}-\mathrm{PAA}$ /Alginate.

\begin{tabular}{cccc}
\hline Isotherms model & \multicolumn{3}{c}{ Parameter } \\
\hline Langmuir & $Q_{\max }$ & $K_{\mathrm{L}}$ & $\mathrm{R}^{2}$ \\
& 176.5 & 0.0083 & 0.9508 \\
& $K_{\mathrm{F}}$ & $n$ & $\mathrm{R}^{2}$ \\
Freundlich & 11.16 & 2.351 & 0.8653
\end{tabular}


Temkin

$\begin{array}{lll}b_{\mathrm{r}} & A_{\mathrm{r}} & \mathrm{R}^{2}\end{array}$

\begin{tabular}{cccc} 
& $b_{\mathrm{r}}$ & $A_{\mathrm{r}}$ & $\mathrm{R}^{2}$ \\
& 57.69 & 0.0641 & 0.9409 \\
Temkin & $K_{\mathrm{LF}}$ & $n$ & $\mathrm{R}^{2}$ \\
Langmuir- Freundlich & 839.8 & 5925 & 0.9808 \\
\hline
\end{tabular}

\subsection{Selective adsorption and recyclability test}

In the selective adsorption experiment, a mixed solution containing $\mathrm{Cu}(\mathrm{II}), \mathrm{Cd}(\mathrm{II})$, $\mathrm{Pb}(\mathrm{II}), \mathrm{Zn}(\mathrm{II}), \mathrm{Mn}(\mathrm{II})$, and $\mathrm{Ni}(\mathrm{II})$ with the same concentration as $50 \mathrm{mg} / \mathrm{L}$ was conducted. As shown in Fig. $7 \mathrm{a}$, the $\mathrm{Pb}$ (II) was preferentially adsorbed with the adsorption efficiency of $79.8 \%$ by $\mathrm{NH}_{2}-\mathrm{PAA} /$ Alginate. The adsorption efficiency of the other type of ions was in the order of $\mathrm{Mn}(\mathrm{II})>\mathrm{Cu}(\mathrm{II})>\mathrm{Ni}$ (II) $>\mathrm{Cd}$ (II) $>\mathrm{Zn}$ (II), within the range of $20 \% \sim 35 \%$, indicating $\mathrm{NH}_{2}$-PAA/Alginate has low selectivity while it can effectively treat the wastewater containing mixed heavy metal ions, such as the mining and smelting wastewater. Table 4 list the parameters of selective adsorption, the difference of $K_{\mathrm{d}}$ may be mainly caused by the difference of electronegativity (2.2 for $\mathrm{Pb}(\mathrm{II}), 1.55$ for $\mathrm{Mn}(\mathrm{II}), 1.9$ for $\mathrm{Cu}(\mathrm{II}), 1.91$ for $\mathrm{Ni}(\mathrm{II}), 1.69$ for $\mathrm{Cd}(\mathrm{II})$ and 1.65 for $\mathrm{Zn}(\mathrm{II})$ ) [22], in addition, the mass-to-charge ratio, stability constant, chemical speciation, size of hydrated, and chelation ability of these bivalent heavy metal ions also lead to the difference of adsorption capacity [9].

The regeneration ability of adsorbents is one of the important indexes as it is closely related to the economy of water treatment technology. The result of influence of $\mathrm{pH}$ experiment indicating that the adsorption-desorption of $\mathrm{Cd}(\mathrm{II})$ on $\mathrm{NH}_{2}$ PAA/Alginate could be facilely achieved by adjusting solution $\mathrm{pH}$. Fig. $7 \mathrm{~b}$ shows that the desorption efficiency of $\mathrm{Cd}(\mathrm{II})$ is high in the $0.1 \mathrm{M} \mathrm{HCl}$ solution, and the adsorption/ desorption performance of $\mathrm{NH}_{2}-\mathrm{PAA} /$ Alginate maintained highly stable in each cycle. For example, the adsorption rate of the first cycle was $52.2 \%$, while the adsorption rate of the fifth cycle decreased slightly to $48.2 \%$. Obviously, the excellent recyclability of $\mathrm{NH}_{2}$-PAA/Alginate could be attributed to its three-dimensional porous structure with 
good mechanical stability.
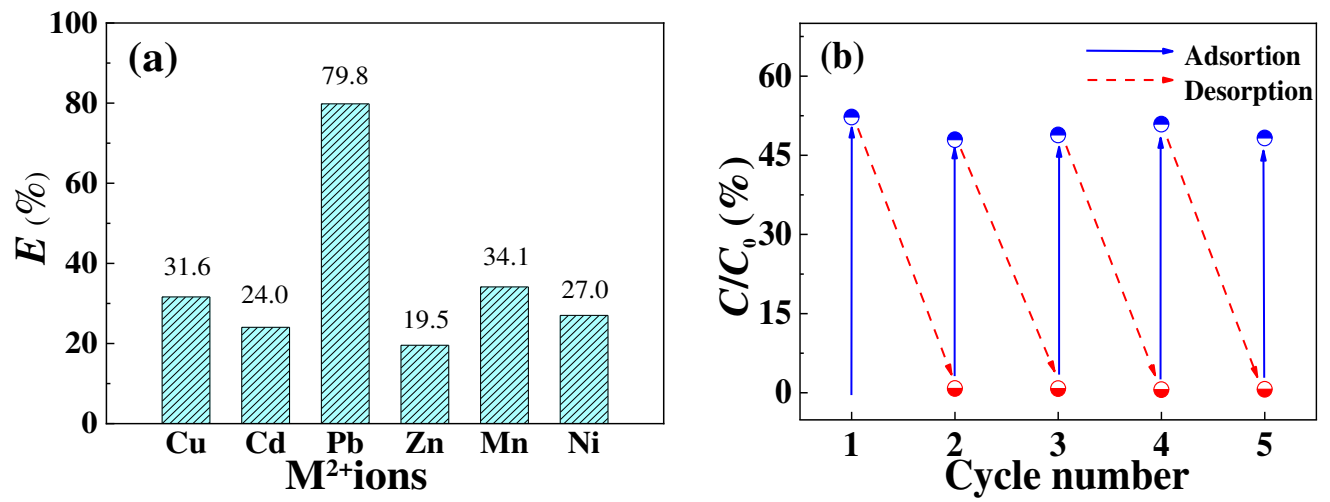

Fig. 7 (a) Selective adsorption of the $\mathrm{NH}_{2}$-PAA/Alginate hydrogel in a mixed solution $\left(C_{0}=50\right.$ $\mathrm{mg} / \mathrm{L}, t=4 \mathrm{~h}, T=298 \mathrm{~K}, \mathrm{pH}=6.0$ ). (b) Recycling of $\mathrm{NH}_{2}$-PAA/Alginate hydrogel in the removal of Cd(II) $\left(C_{0}=50 \mathrm{mg} / \mathrm{L}, t=4 \mathrm{~h}, T=298 \mathrm{~K}, \mathrm{pH}=6.0\right)$.

Table 4 The distribution adsorption coefficient of the five mixed ions

\begin{tabular}{ccccc}
\hline Ions & $\left.q_{\mathrm{e}} / \mathrm{g} / \mathrm{g}\right)$ & $E / \%$ & $K_{\mathrm{d}} /(\mathrm{L} / \mathrm{g})$ & Electronegativity \\
\hline $\mathrm{Pb}(\mathrm{II})$ & 39.91 & 79.82 & 3.96 & 2.2 \\
$\mathrm{Mn}(\mathrm{II})$ & 17.07 & 34.13 & 0.52 & 1.55 \\
$\mathrm{Cu}(\mathrm{II})$ & 15.82 & 31.63 & 0.46 & 1.9 \\
$\mathrm{Ni}(\mathrm{II})$ & 13.51 & 27.02 & 0.37 & 1.91 \\
$\mathrm{Cd}(\mathrm{II})$ & 12.02 & 24.04 & 0.32 & 1.69 \\
$\mathrm{Zn}(\mathrm{II})$ & 9.78 & 19.56 & 0.24 & 1.65 \\
\hline
\end{tabular}

\subsection{Adsorption mechanism}

The adsorption mechanism between adsorbent and heavy metal ions plays an important role for adsorption design. In the previous discussion, a preliminarily conclusion could be inferred that the $\mathrm{Cd}(\mathrm{II})$ adsorption by $\mathrm{NH}_{2}-\mathrm{PAA} /$ Alginate was dominated by ion exchange and chemical adsorption. To further explore the adsorption mechanism, the XPS was used to analyze the chemical state of element in $\mathrm{NH}_{2}-$ PAA/Alginate and Cd-NH2-PAA/Alginate. The XPS survey scan spectra (Fig. 8a) show photoelectron lines at binding energies of about 284, 347, 399 and $531 \mathrm{eV}$ attributed to $\mathrm{C} 1 \mathrm{~s}, \mathrm{Ca} 2 \mathrm{p}, \mathrm{N} 1 \mathrm{~s}$ and $\mathrm{O} 1 \mathrm{~s}$, respectively. The characteristic peaks of $\mathrm{Cd} 3 \mathrm{~d}_{5 / 2}$ and $\mathrm{Cd} 3 \mathrm{~d}_{3 / 2}$ 
at 405 and $410 \mathrm{eV}$ appeared obvious in $\mathrm{Cd}-\mathrm{NH}_{2}-\mathrm{PAA} /$ Alginate, while the characteristic peak of $\mathrm{Ca} 2 \mathrm{p}$ became weaker, indicating that the part of $\mathrm{Ca}(\mathrm{II})$ was replaced by $\mathrm{Cd}(\mathrm{II})$ in the adsorption process [37]. This result also can be inferred by XPS element analysis in Table 1, the content of $\mathrm{Ca}$ elements decreased from $1.6 \%$ to $0.7 \%$, while the content of $\mathrm{Cd}$ increased to $1.16 \%$.

The high-resolution XPS spectra show that the binding energies of N1s had significant changed before and after adsorbing Cd(II) (Fig. 8c). There is mainly one typical $\mathrm{N} 1 \mathrm{~s}$ peak at $399.75 \mathrm{eV}$ in $-\mathrm{NH}_{2}$ groups of $\mathrm{NH}_{2}-\mathrm{PAA} /$ Alginate, while after the adsorption of $\mathrm{Cd}(\mathrm{II})$, the characteristic peak shifted to higher positions at $400.56 \mathrm{eV}$, which indicates the formation of coordination bond between amino group and $\mathrm{Cd}(\mathrm{II})$. This can be interpreted that the $\mathrm{Cd}$ atom is able to accept isolated electron pair at $\mathrm{N}$ atom to form new compounds, and reducing the electron densities of the $\mathrm{N}$ atom [38]. In the high-resolution XPS spectra of O1s (Fig. 8d), there was slight shift of O1s peaks in $\mathrm{Cd}-\mathrm{NH}_{2}-\mathrm{PAA} /$ Alginate, and the integral area ratio of the two peaks of $\mathrm{O} 1 \mathrm{~s}$ at 532.5 $\mathrm{eV}(\mathrm{C}=\mathrm{O})$ and $531.2 \mathrm{eV}(\mathrm{C}-\mathrm{O})$ for $\mathrm{NH}_{2}-\mathrm{PAA} /$ Alginate and $\mathrm{Cd}-\mathrm{NH}_{2}-\mathrm{PAA} /$ Alginate increased from 0.430 to 0.491 . indicating that the binding of $\mathrm{Cd}(\mathrm{II})$ also occurred at $\mathrm{O}$ atoms of hydroxyl group [27]. The results reveal that the $\mathrm{Cd}(\mathrm{II})$ exchanged with $\mathrm{Ca}(\mathrm{II})$ and then coordinated with amino and hydroxyl groups in $\mathrm{NH}_{2}-\mathrm{PAA} /$ Alginate.
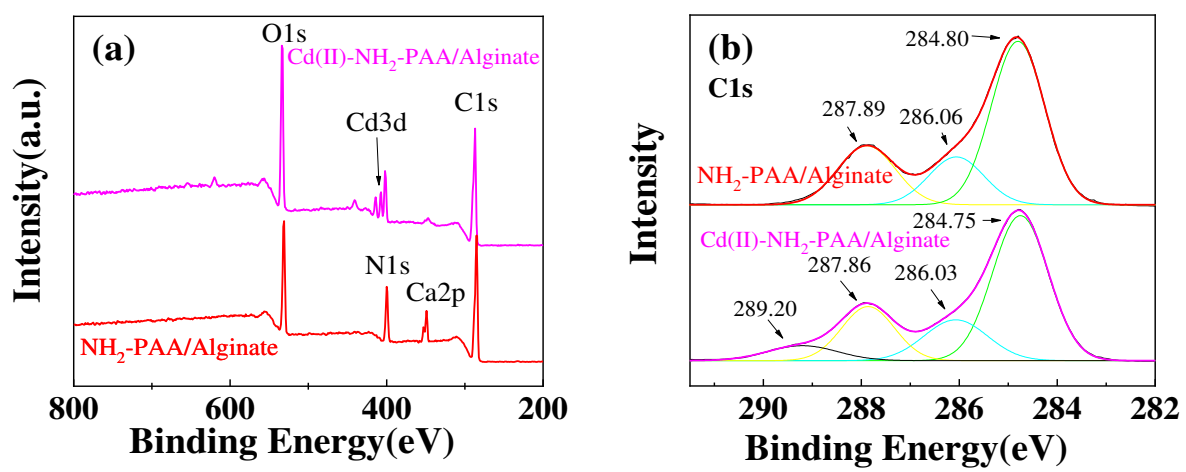

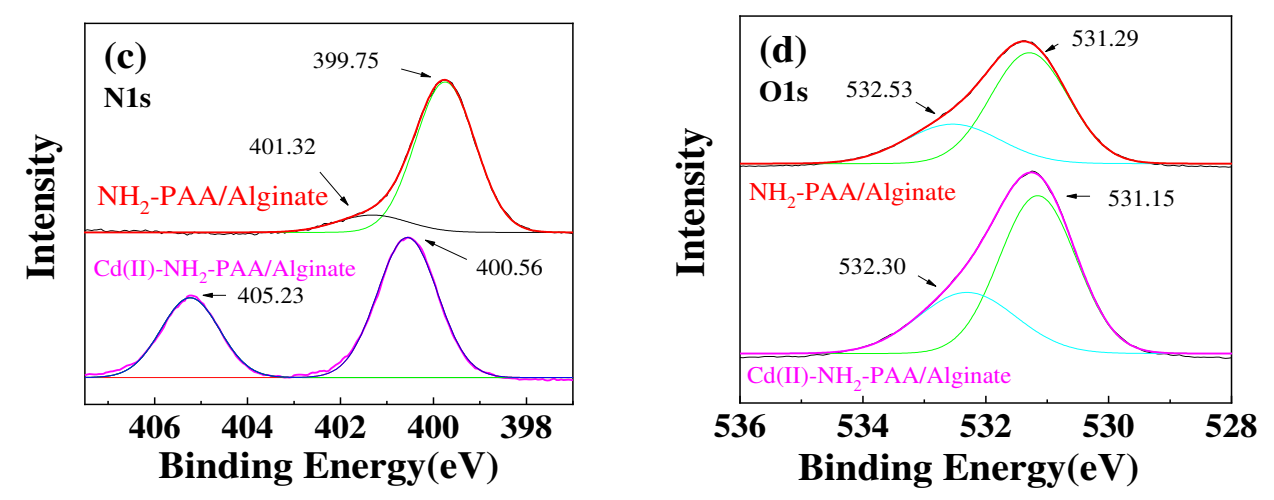

Fig. 8 The XPS spectra of $\mathrm{NH}_{2}$-PAA/Alginate hydrogel, (a) total survey scan of XPS spectra; high-resolution XPS spectra of (b) C1s; (c) N1s; (d) O1s.

\section{Conclusions}

In this study, a new hydrogel with double network interpenetrating structure was well designed and prepared via simple radical polymerization and amino modification. The moisture of $\mathrm{NH}_{2}-\mathrm{PAA} /$ Alginate was $90 \%$, while the it exhibited the good mechanical strength. The $\mathrm{Cd}(\mathrm{II})$ adsorption on $\mathrm{NH}_{2}-\mathrm{PAA} /$ Alginate was strongly dependent on $\mathrm{pH}$ and weakly dependent on ionic strength. The adsorption capacities were as high as $176.5 \mathrm{mg} / \mathrm{g}$ for $\mathrm{Cd}(\mathrm{II})$, and the equilibrium reached in $150 \mathrm{~min}$. Besides, $\mathrm{NH}_{2}$-PAA/Alginate had excellent adsorption capacity for various heavy metal ions in a mixed solution, and can be used to effectively treat mining and smelting industrial wastewater. In addition, the $\mathrm{NH}_{2}-\mathrm{PAA} /$ Alginate could be easily regenerated and highly reused. The result of adsorption mechanism analysis illustrated that amino and hydroxyl groups in $\mathrm{NH}_{2}-\mathrm{PAA} /$ Alginate involve in the adsorption process by chemical coordination with $\mathrm{Cd}(\mathrm{II})$. This wok opens a new window to develop high performance sorbents for the removal heavy metal ions. In summary, the $\mathrm{NH}_{2}$-PAA/Alginate will be very suitable materials for the adsorption of heavy metal ions from large volumes of aqueous solutions in environmental pollution cleanup in the near future.

\section{Acknowledgments}

This work was supported by the National Natural Science Foundation of China [52070078, 51708204, 51774128], Hunan Provincial Natural Science Foundation of China [2018JJ3125, 2018JJ4009 and 2019JJ50137], and Scientific Research Project of 
the Education Department of Hunan Province [19C0568, 17C0463].

\section{References}

1. S. Vasudevan, Int. J. Waste Resour. 6, (2016).

2. A. M. Riederer, A. Belova, B. J. George, and P. T. Anastas, Environ. Sci. Technol. 47, 1137 (2013).

3. K. Fu, X. Liu, D. Yu, J. Luo, Z. Wang, and J. C. Crittenden, Environ. Sci. Technol. 54, $16212(2020)$.

4. Q. Chen, W. Xu, and Q. Ge, Environ. Sci. Technol. 52, 4464 (2018).

5. L. Ma, Q. Wang, S. M. Islam, Y. Liu, S. Ma, and M. G. Kanatzidis, J. Am. Chem. Soc. 138, 2858 (2016).

6. H. Zhang, X. Quan, S. Chen, X. Fan, G. Wei, and H. Yu, Environ. Sci. Technol. 52, 4827 (2018).

7. A. Martín-Domínguez, M. L. Rivera-Huerta, S. Pérez-Castrejón, S. E. GarridoHoyos, I. E. Villegas-Mendoza, S. L. Gelover-Santiago, P. Drogui, and G. Buelna, Sep. Purif. Technol. 200, 266 (2018).

8. X. Du, S. Cui, X. Fang, Q. Wang, and G. Liu, J. Environ. Chem. Eng. 8, 104530 (2020).

9. G. Zhou, J. Luo, C. Liu, L. Chu, and J. Crittenden, Water Res. 131, 246 (2018).

10. Y. Kobayashi, F. Ogata, T. Nakamura, and N. Kawasaki, J. Environ. Chem. Eng. 8, 103687 (2020).

11. J. Li, Q. Duan, Z. Wu, X. Li, K. Chen, G. Song, A. Alsaedi, T. Hayat, and C. Chen, Chem. Eng. J. 383, 123189 (2020).

12. W. Cui, X. Zhang, C. I. Pearce, Y. Chen, S. Zhang, W. Liu, M. H. Engelhard, L. Kovarik, M. Zong, H. Zhang, E. D. Walter, Z. Zhu, S. M. Heald, M. P. Prange, J. J. De Yoreo, S. Zheng, Y. Zhang, S. B. Clark, P. Li, Z. Wang, and K. M. Rosso, 
Environ. Sci. Technol. 53, 11043 (2019).

13. S. Z. Mohammadi, Z. Safari, and N. Madady, J. Inorg. Organomet. Polym. Mater. 30, 3199 (2020).

14. L. Huang, M. He, B. Chen, and B. Hu, Chemosphere 199, 435 (2018).

15. I. Ali, Chem. Rev. 112, 5073 (2012).

16. M. A. Haq, Y. Su, and D. Wang, Mater. Sci. Eng. C 70, 842 (2017).

17. E. M. Ahmed, J. Adv. Res. 6, 105 (2015).

18. J.-Y. Sun, X. Zhao, W. R. K. Illeperuma, O. Chaudhuri, K. H. Oh, D. J. Mooney, J. J. Vlassak, and Z. Suo, Nature 489, 133 (2012).

19. S. De Koker, J. Cui, N. Vanparijs, L. Albertazzi, J. Grooten, F. Caruso, and B. G. De Geest, Angew. Chemie - Int. Ed. 55, 1334 (2016).

20. Y. S. Zhang and A. Khademhosseini, Science (80-. ). 356, eaaf3627 (2017).

21. M. Khan and I. M. C. Lo, Water Res. 106, 259 (2016).

22. J. Tang, J. Huang, G. Zhou, and S. Liu, J. Chem. Thermodyn. 141, 105918 (2020).

23. Y. Tan, Y. Zhang, Y. Zhang, J. Zheng, H. Wu, Y. Chen, S. Xu, J. Yang, C. Liu, and Y. Zhang, Chem. Mater. 32, 7670 (2020).

24. Y. Zhou, C. Wan, Y. Yang, H. Yang, S. Wang, Z. Dai, K. Ji, H. Jiang, X. Chen, and Y. Long, Adv. Funct. Mater. 29, 1806220 (2019).

25. H. Wang, X. Hu, Y. Guo, C. Qiu, S. Long, D. Hao, X. Cai, W. Xu, Y. Wang, and Y. Liu, J. Chem. Technol. Biotechnol. 93, 2447 (2018).

26. G. Zhou, C. Liu, L. Chu, Y. Tang, and S. Luo, Bioresour. Technol. 219, 451 (2016).

27. Z. Ahmed, P. Wu, L. Jiang, J. Liu, Q. Ye, Q. Yang, and N. Zhu, Colloids Surfaces A Physicochem. Eng. Asp. 604, 125285 (2020). 
28. J. Shi, H. Zhang, Y. Yu, X. Zou, W. Zhou, J. Guo, Y. Ye, and Y. Zhao, J. Inorg. Organomet. Polym. Mater. 30, 2114 (2020).

29. H. Li, H. Zheng, Y. J. Tan, S. B. Tor, and K. Zhou, ACS Appl. Mater. Interfaces 13, $12814(2021)$.

30. L. Chu, C. Liu, G. Zhou, R. Xu, Y. Tang, Z. Zeng, and S. Luo, J. Hazard. Mater. 300, 153 (2015).

31. L. Gong, Y. Kong, H. Wu, Y. Ge, and Z. Li, J. Inorg. Organomet. Polym. Mater. 31, 659 (2021).

32. M. Hasanpour and M. Hatami, Adv. Colloid Interface Sci. 284, 102247 (2020).

33. R. Katiyar, A. K. Patel, T.-B. Nguyen, R. R. Singhania, C.-W. Chen, and C.-D. Dong, Bioresour. Technol. 328, 124829 (2021).

34. Y. Yu, L. Shang, J. Guo, J. Wang, and Y. Zhao, Nat. Protoc. 13, 2557 (2018).

35. A. Hashem, A. J. Fletcher, M. El-Sakhawy, L. A. Mohamed, and S. Farag, J. Polym. Environ. 28, 2498 (2020).

36. L. Guan, H. Kang, W. Liu, and D. Tian, Int. J. Biol. Macromol. 177, 48 (2021). 37. W. Zhang, X. He, G. Ye, R. Yi, and J. Chen, Environ. Sci. Technol. 48, 6874 (2014).

38. G. Zhou, J. Luo, C. Liu, L. Chu, J. Ma, Y. Tang, Z. Zeng, and S. Luo, Water Res. 89, 151 (2016). 
Figures

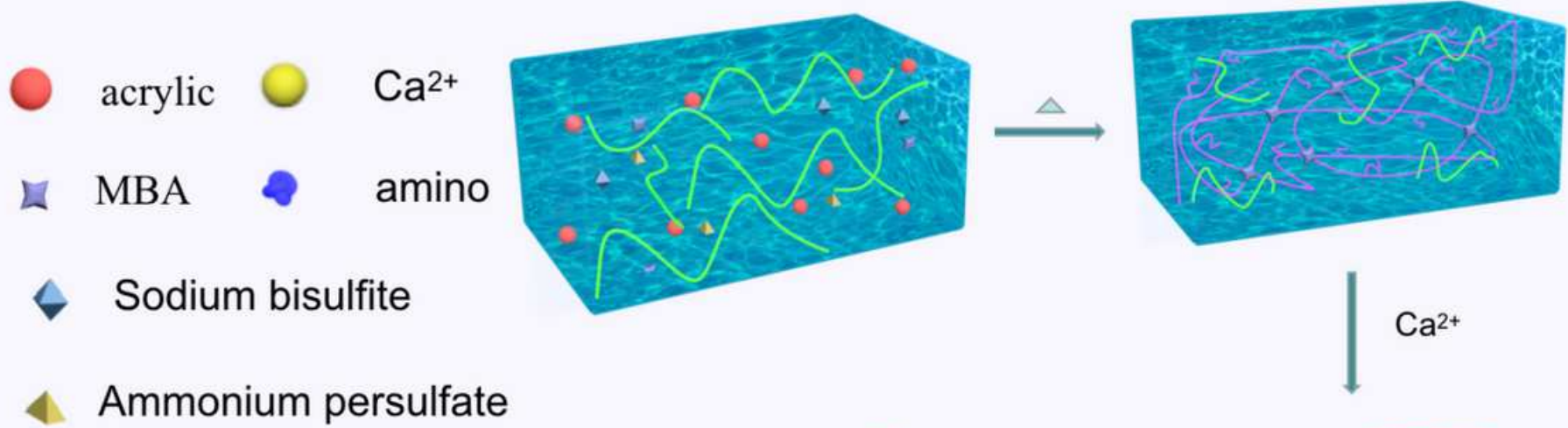

Sodium alginate

Acrylic chain
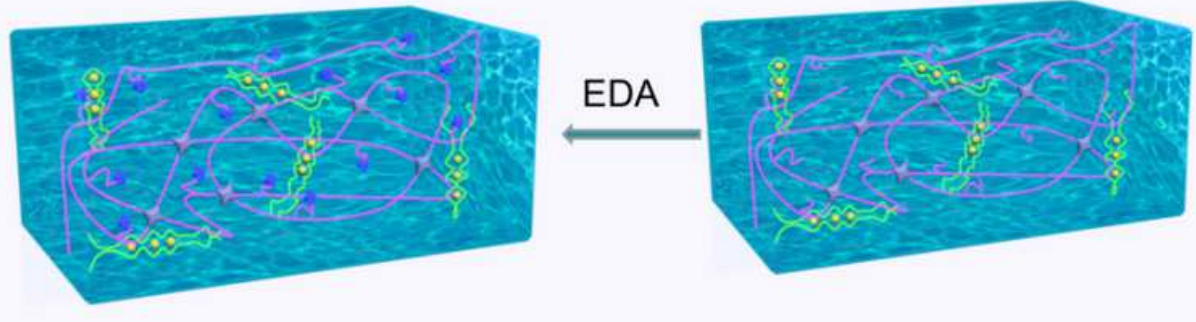

Figure 1

Mechanisms of converting the composite into NH2-PAA/Alginate DN hydrogels.

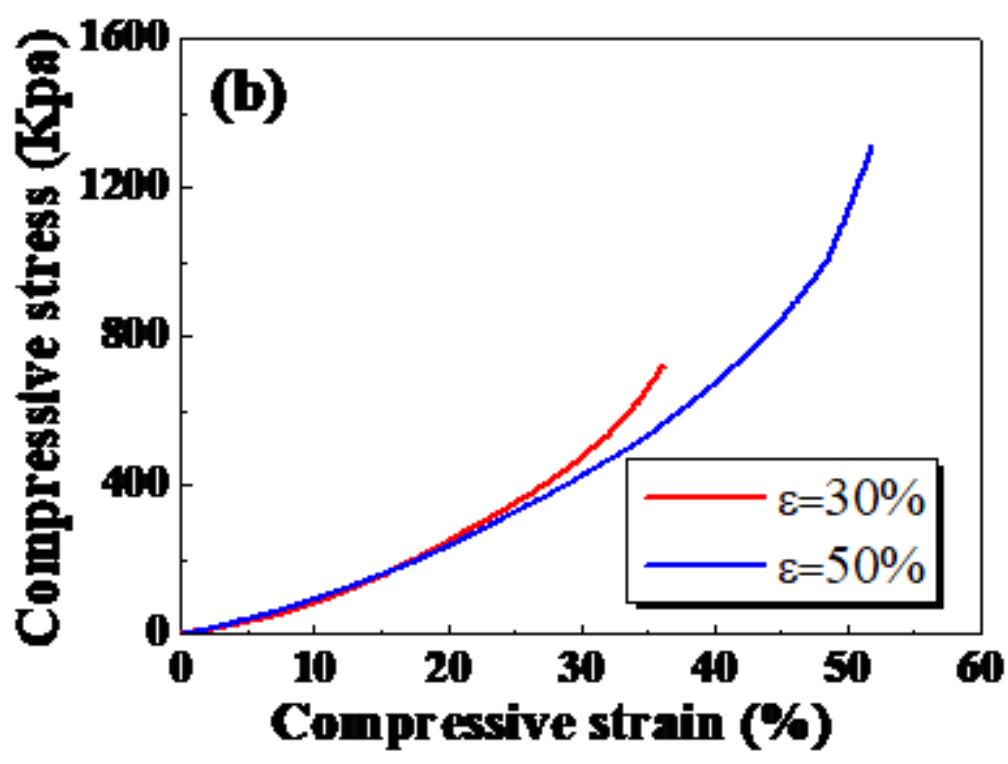

Figure 2

(a) The SEM image of NH2-PAA/Alginate. (b) Typical consecutive loading curves with gradually increased strain on NH2-PAA/Alginate. 

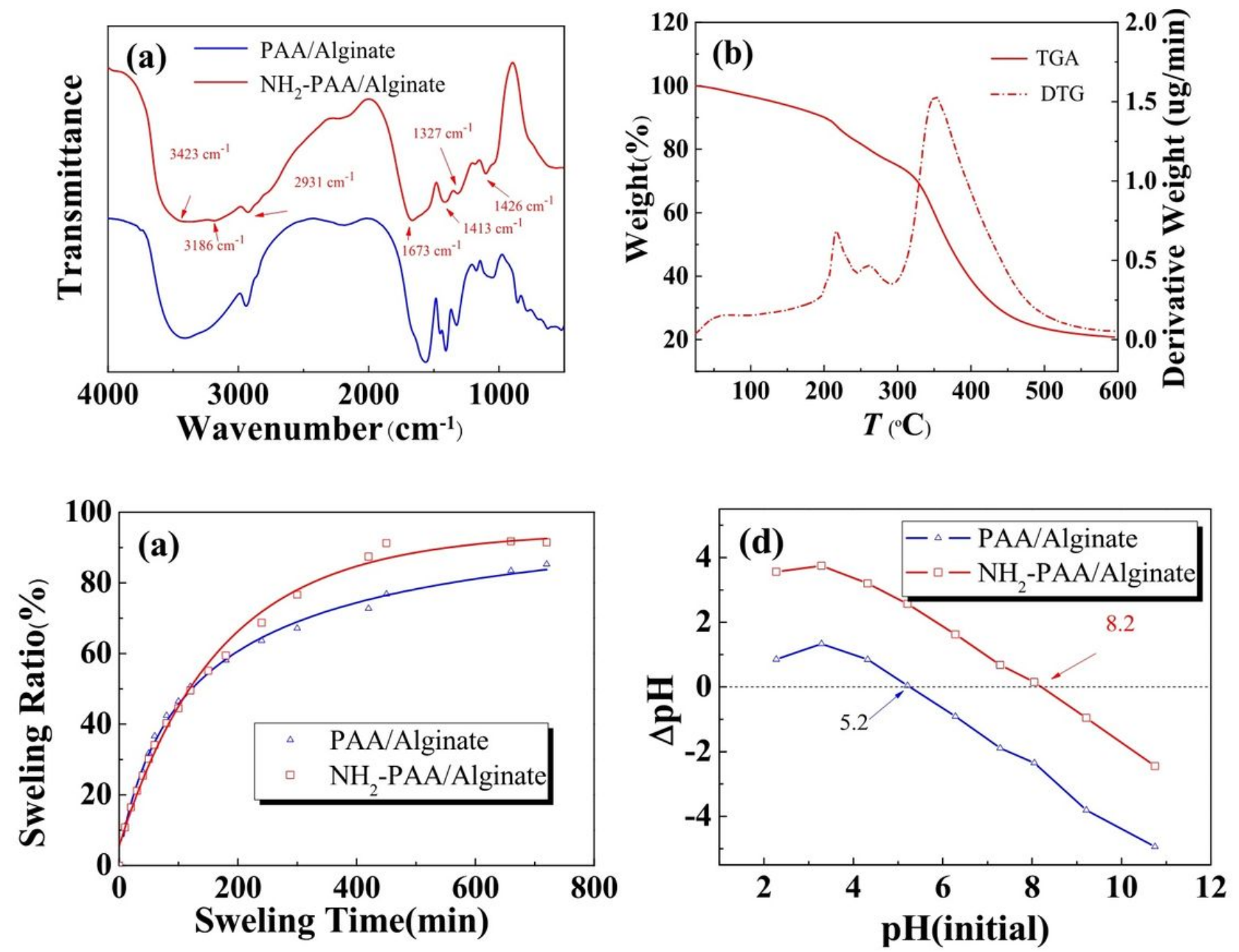

Figure 3

(a) The FTIR spectra. (b) The TGA and DTG curves. (c) The swelling curves. (d) The pHpzc measure of the hydrogel by $\Delta \mathrm{pH}$ method. 

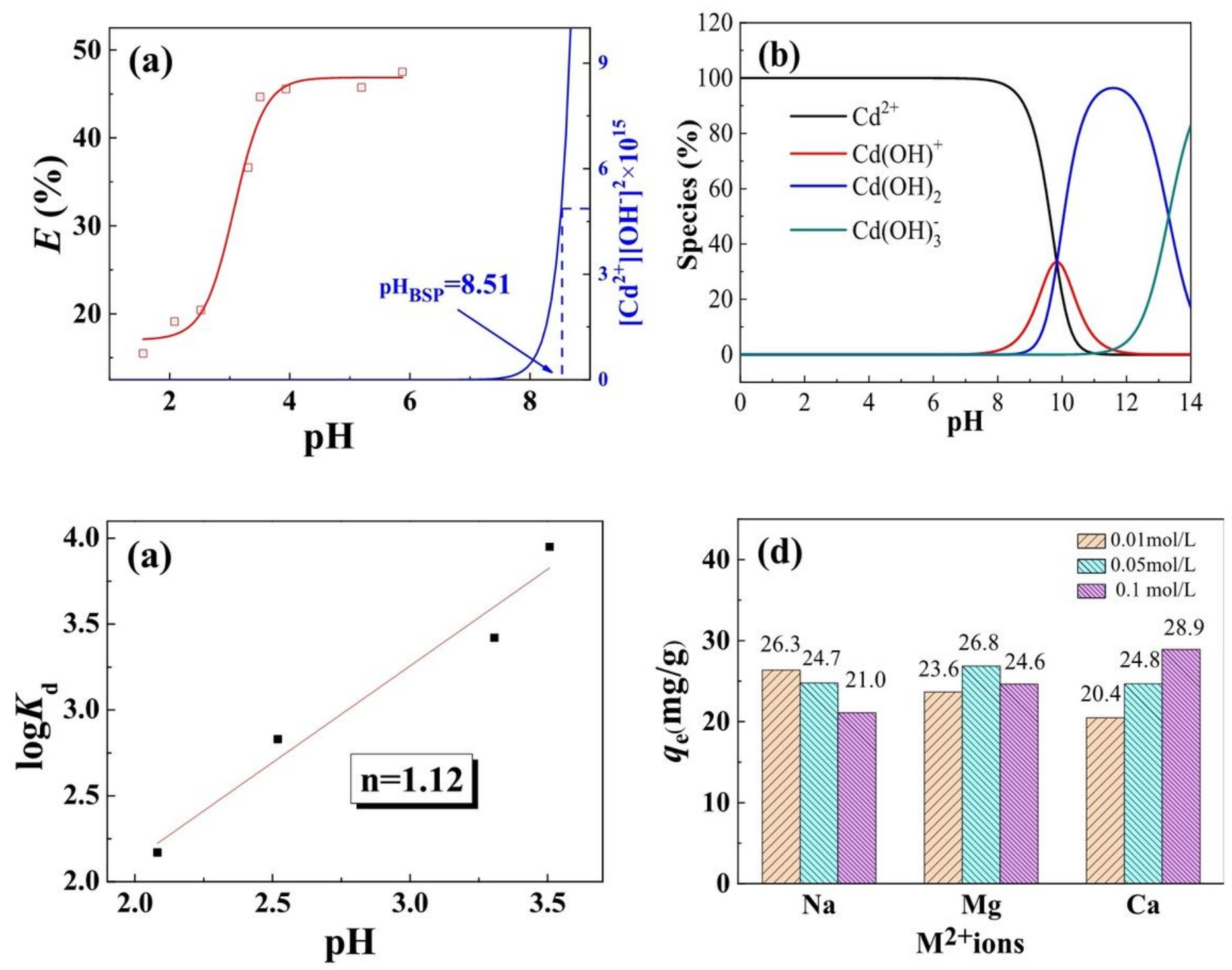

Figure 4

(a) Effect of $\mathrm{pH}$ on $\mathrm{Cd}(\mathrm{II})$ adsorption by NH2-PAA/Alginate (CO $=50 \mathrm{mg} / \mathrm{L}, \mathrm{t}=4 \mathrm{~h}, \mathrm{~T}=298 \mathrm{~K}$ ). (b) Distribution of radionuclide species in aqueous solutions. (c) Linear plot of logKd and pH. (d) Effect of ion species and ionic strength on adsorption for $\mathrm{Cd}(\mathrm{II})(\mathrm{CO}=50 \mathrm{mg} / \mathrm{L}, \mathrm{t}=4 \mathrm{~h}, \mathrm{~T}=298 \mathrm{~K}, \mathrm{pH}=6.0)$. 

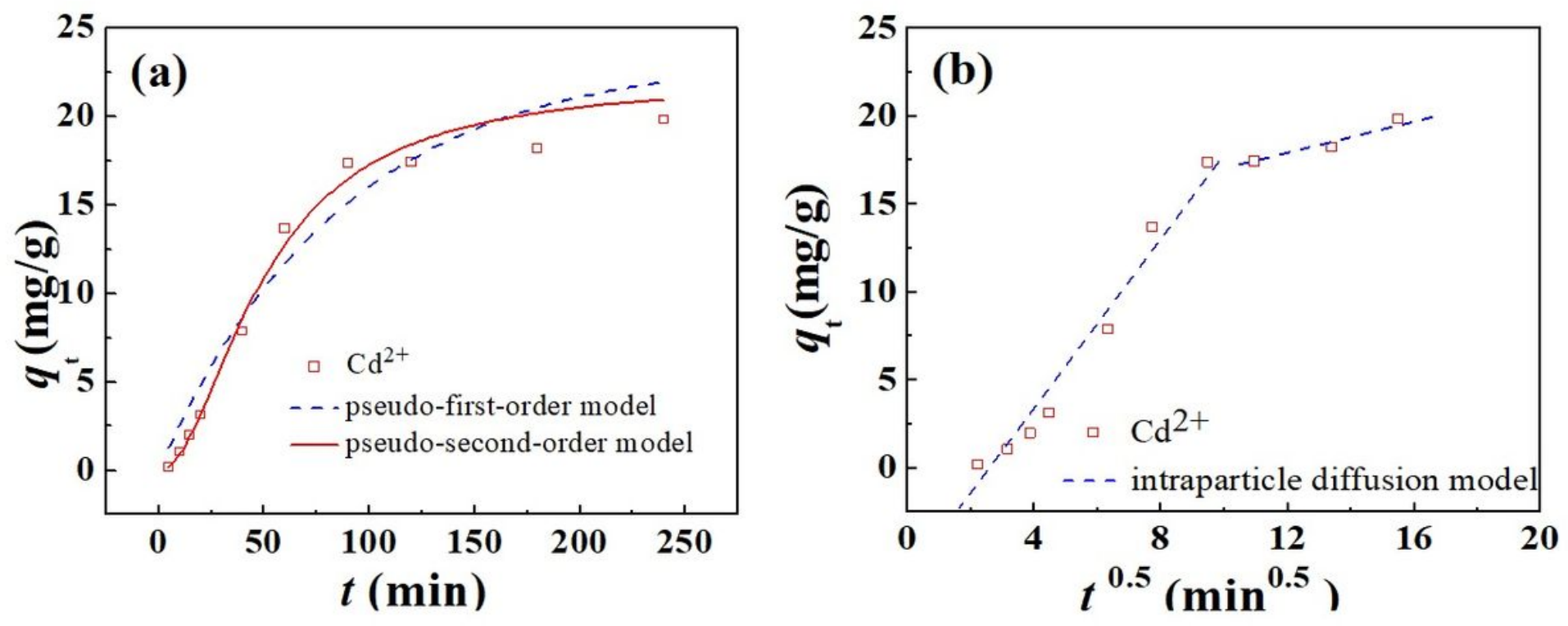

Figure 5

Time-dependent $\mathrm{Cd}(\mathrm{II})$ sorption on hydrogel, the data are fittings to the Pseudo-first-order, Pseudo-secondorder models and intraparticle diffusion model ( $\mathrm{C} 0=50 \mathrm{mg} / \mathrm{L}, \mathrm{T}=25 \mathrm{Z}, \mathrm{pH}=6.0)$.
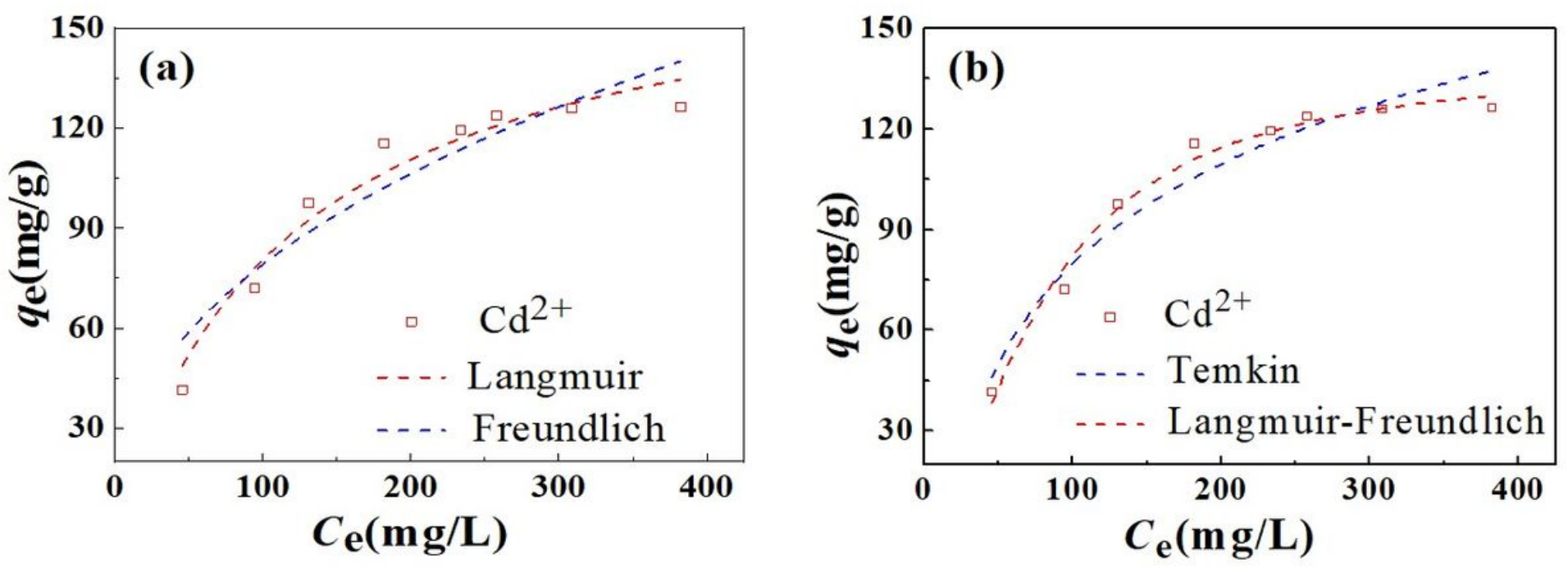

Figure 6

The isothermal adsorption curves of $\mathrm{Cd}(\mathrm{II})$ by NH2-PAA/Alginate $(\mathrm{t}=4 \mathrm{~h}, \mathrm{~T}=298 \mathrm{~K}, \mathrm{pH}=6.0)$. 

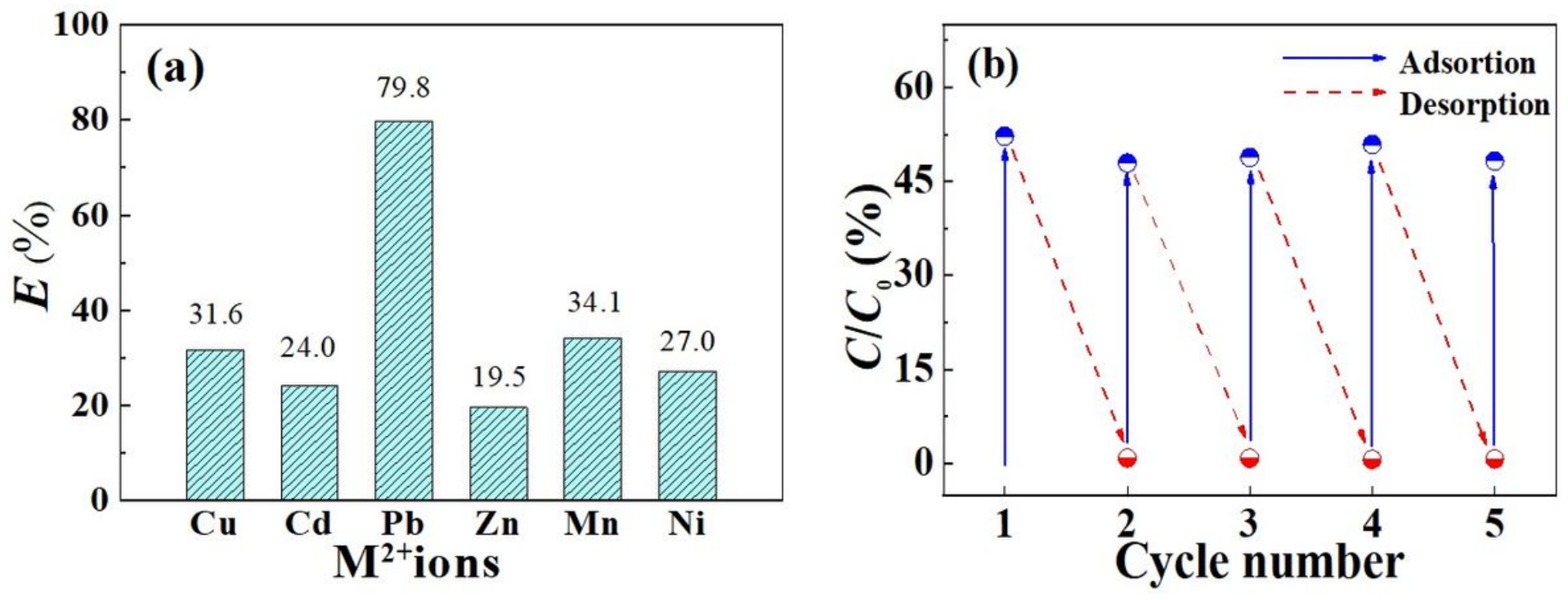

Figure 7

(a) Selective adsorption of the NH2-PAA/Alginate hydrogel in a mixed solution ( $\mathrm{CO}=50 \mathrm{mg} / \mathrm{L}, \mathrm{t}=4 \mathrm{~h}, \mathrm{~T}=$ $298 \mathrm{~K}, \mathrm{pH}=6.0)$. (b) Recycling of NH2-PAA/Alginate hydrogel in the removal of $\mathrm{Cd}(\mathrm{II})(\mathrm{CO}=50 \mathrm{mg} / \mathrm{L}, \mathrm{t}=$ $4 \mathrm{~h}, \mathrm{~T}=298 \mathrm{~K}, \mathrm{pH}=6.0)$. 

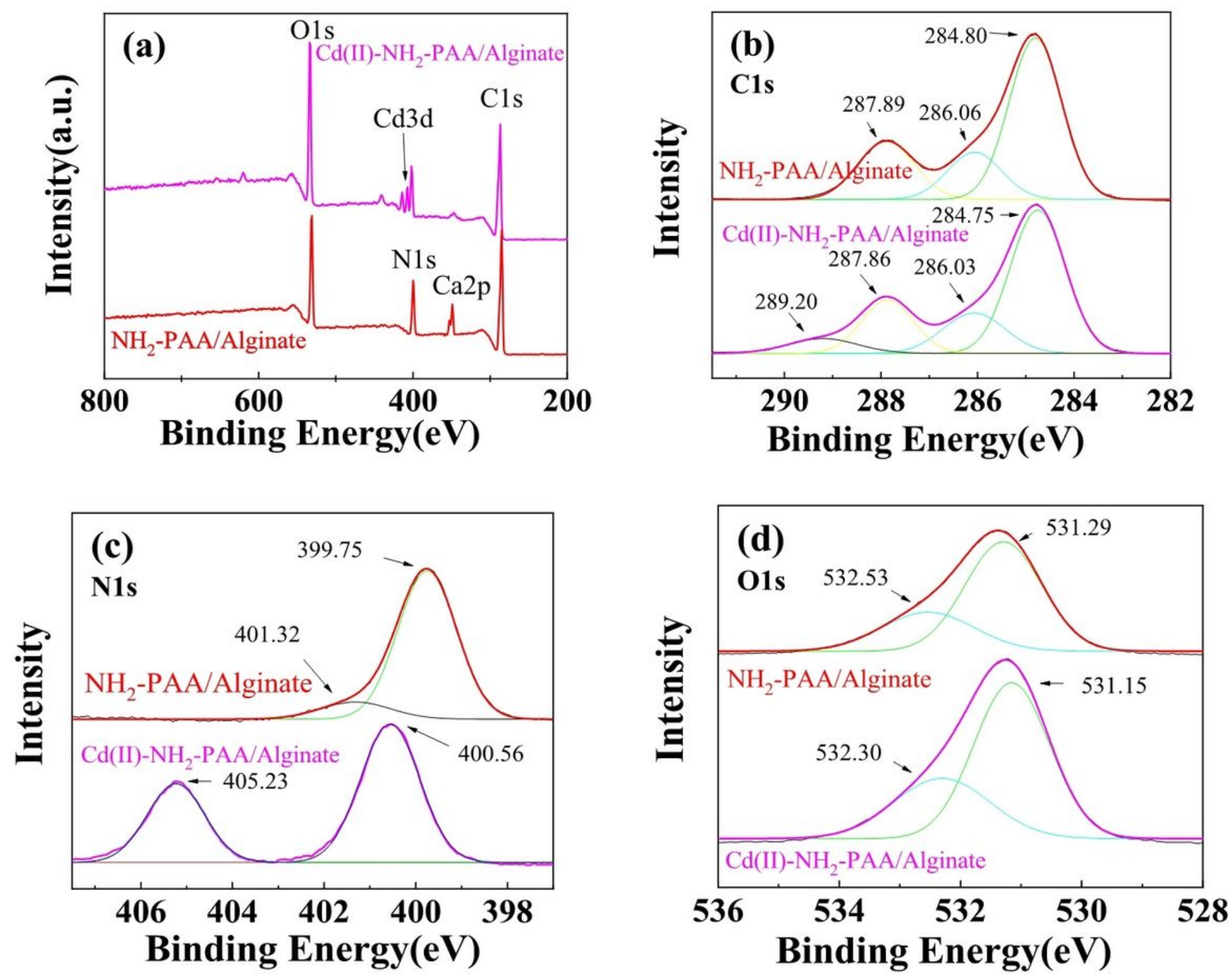

Figure 8

The XPS spectra of NH2-PAA/Alginate hydrogel, (a) total survey scan of XPS spectra; high-resolution XPS spectra of (b) C1s; (c) N1s; (d) 01s. 